\title{
Maximum Torque Control of Induction Traction Motor Based on DQ Axis Voltage Regulation
}

\author{
Guo-Bin SUN ${ }^{1, a}$, Shu-Jia MU ${ }^{1, b,{ }^{*}}$, Hua LI ${ }^{2, c, *}$ and Fei LIN ${ }^{2, d}$ \\ ${ }^{1}$ CRRC QINGDAO SIFANG ROLLING STOCK RESEARCH INSTITUTE CO., Ltd, Qingdao, 266031, \\ China \\ ${ }^{2}$ BEIJING JIAOTONG UNIVERSITY, Beijing, 100044, China \\ ausasoldier_sgb@163.com, ${ }^{\text {b }}$ mushujia8247@163.com, ${ }^{\mathrm{c}} 15126016 @$ bjtu.edu.cn
}

\begin{abstract}
Keywords: Weakening control; Induction motor; Indirect-field orientation.
\end{abstract}
\begin{abstract}
In the high power traction driving system, induction motor is widely used with its advantages of strong structure, high reliability and low cost. When the voltage source inverter is used as the driving device of the induction motor and the motor speed exceeds the rated speed, it is required to consider the limit of DC bus voltage and inverter rated current. Therefore, an appropriate field weakening control strategy is needed to reduce the rotor flux, and to enhance the output torque of the motor when induction motor operation in the filed weakening region. According to the above problems, considering the DC side bus voltage limit and the inverter current limit, this paper focuses on the analysis the current distribution of induction motor in the field weakening region to achieve maximum torque output, and proposes a method which achieve the maximum torque output in full speed range based on the DQ axis voltage regulation. In the final, the simulation results are verified on the MATLAB/Simulink simulation platform.
\end{abstract}

\section{Introduction}

In rail transit, the asynchronous motor is widely used for its simple structure and strong adaptability. For high power traction drive system, it is very important to achieve high performance control performance in the whole speed range. Especially when the motor operates in the field weakening region, choosing appropriate control strategy has a very important influence on the control performance of induction motor, due to the limitation of DC side voltage, stator current nonlinear factors and the impact of back EMF.

In the high power traction driving system, it is very difficult to select the appropriate rotor flux in the high-speed region of induction motor. Too large or too small a value of rotor flux may lead to a decrease in developed torque, and thus the deterioration of motor operating performance, such as dynamic behavior and conversion efficiency.

According to this, it has been proposed a lot of the flux weakening control strategy. The simplest method is to let the rotor flux reference be inversely proportional to the rotor speed [1,2]. In [1], the operation principle of the $1 / \omega_{r}$ method is explained. The main problem of this control strategy is that the rotor flux is not properly selected. The researches made in [2] take the voltage limitation into consideration based on the conventional $1 / \omega_{r}$ method. Weakening control strategy [3] adopted in accordance with the motor model to calculate a reasonable stator excitation current command. Since the calculation in accordance with the steady-state motor model parameters to obtain the parameters of the current command of highly sensitive, especially in certain motor parameters affected by magnetic saturation, frequency and temperature will change dramatically. Transient model of induction motor are used to calculate the reference current command, which improves its robustness to a certain extent in [3]. In [4], the reference flux current command value calculated by adding a stator voltage loop, thereby greatly enhancing the robustness of the motor parameters. The input of voltage controller is the error between the maximum output voltage limit and the actual output voltage. The paper [5] pointed out that an algebraic loop may be existed in the method of voltage 
controller. To avoid the algebraic loop, PI controller is replaced by integral controller. Off-line weakening control strategy is mainly look-up table, the torque current and flux current command value are obtained by the look-up table in [6].

This paper established the steady-state mathematical model of the induction motor, the voltage and current constraints are researched under the full speed range. By analyzing the constraints, based on research results, we propose a maximum torque output of weakening control method. The method is based on the rotor field oriented vector control, in synchronization with the rotation of the rotor flux M-T coordinates, according to the DQ axis stator voltage regulation, achieves the maximum torque output in weakening field.

In this paper, section 2 establish the state mathematical model of the induction motor, and analyzes the DC voltage limits, current limits. According to the induction motor in different workspaces current and voltage analysis, a maximum torque output weakening control strategy is obtained in the field weakening based on DQ axis voltage regulation in section 3. This method is verified on the MATLAB/Simulink simulation platform in section 4.

\section{Current and voltage limitation of induction motor in the field weakening region}

When the induction motor operates in the field weakening region, the main objective is to ensure control of the maximum torque output and full utilization of the motor and the inverter capacity. The limitation of the rated current of the motor in the field weakening region and the DC bus voltage are shown in Eq. 1.

$$
\begin{aligned}
& i_{s q}^{2}+i_{s d}^{2} \leq I_{s \max }^{2} \\
& u_{s q}^{2}+u_{s d}^{2} \leq V_{s \max }^{2}
\end{aligned}
$$

Where $u_{s d}$ and $u_{s q}$ is d, q-axis stator voltage, $i_{s d}$ and $i_{s q}$ is d, q-axis current, $I_{s \text { max }}$ is the rated current of motor and inventor, $V_{s \max }$ is the maximum output voltage of inverter.

For the voltage-source inverter system, in the synchronous rotating coordinate system, according to the rotor field orientation, the stator voltage equation is shown below:

$$
\left\{\begin{array}{l}
u_{s d}=\left(R_{s}+\frac{L_{m}^{2}}{L_{r}^{2}} R_{r}\right) i_{s d}+\sigma L_{s} p i_{s d}-\omega_{e} \sigma L_{s} i_{s q}-\frac{L_{m}}{L_{r}^{2}} R_{r} \psi_{r} \\
u_{s q}=\left(R_{s}+\frac{L_{m}^{2}}{L_{r}^{2}} R_{r}\right) i_{s q}+\sigma L_{s} p i_{s q}+\omega_{e} \sigma L_{s} i_{s d}+\frac{L_{m}}{L_{r}} \omega_{r} \psi_{r}
\end{array}\right.
$$

Where $\sigma=1-L_{m}^{2} /\left(L_{r} L_{s}\right)$ is the leakage inductance, $\psi_{r}$ is the rotor flux, $\omega_{e}$ is the synchronous angular velocity.

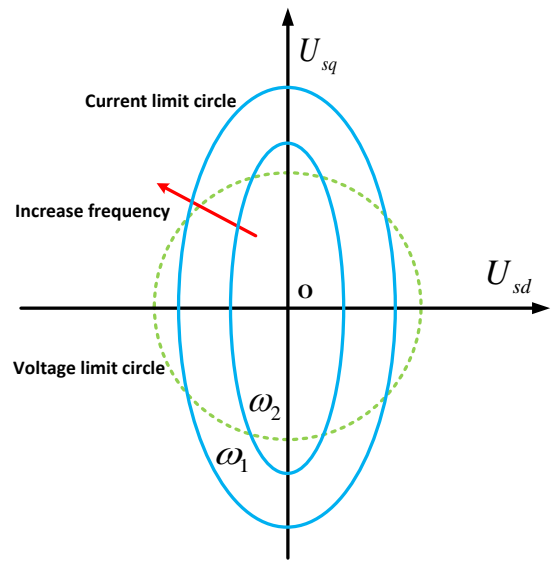

Fig. 1 the limit of current and voltage in the field weakening region

When the induction motor operates in the high-speed region, the voltage shared by stator resistance is so small that can be neglected. In the steady state analysis, the differential phase is zero, so the Eq. 2 can be simplified as: 


$$
\begin{aligned}
& u_{s d}=-\omega_{e} \sigma L_{s} i_{s q} \\
& u_{s q}=\omega_{e} L_{s} i_{s d}
\end{aligned}
$$

According to Eq. 1 and Eq. 3, the DQ axis voltage limit curve can be shown in Fig. 1 when induction motor operates in the field weakening region. As can be seen from Fig. 1, in the DQ axis stator voltage coordinates, as the motor speed increases, the current limit circle constantly extended. When the speed reaches a certain level, voltage limit circle is all in the current limit circle, at this time, only need to consider the voltage limit.

\section{DQ axis stator voltage distribution for the maximum torque output}

The full speed range can be divided into three areas, the constant torque region (ws $<$ wbase), the constant power region (wbase $<$ ws $<$ w1) and the constant voltage region (ws $>$ w1), as shown in Fig. 2.

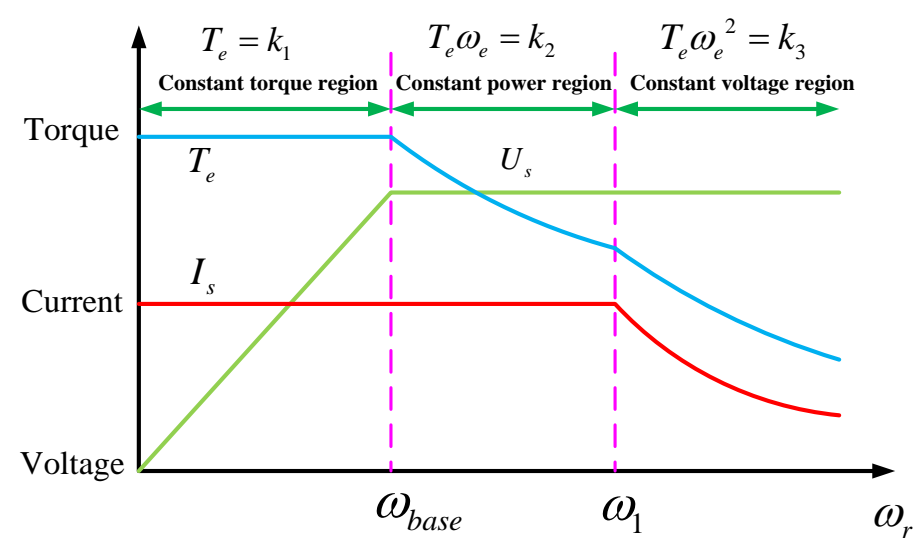

Fig. 2 division of induction motor operating region

In synchronous rotating coordinate system, according to the Eq. 3, the equation of motor output torque can be obtained.

$$
T_{e}=\frac{3}{2} n_{p} \frac{L_{m}{ }^{2}}{L_{r}} I_{s d} I_{s q}=-\frac{3}{2} n_{p} \frac{L_{m}^{2}}{L_{r} \sigma L_{s}^{2} \omega_{e}^{2}} U_{s q} U_{s d}=k U_{s q} U_{s d}
$$

From Eq. 4, we can make $F=T e / k=U_{s q} U_{s d}$. The size of $F$ determines the size of the motor output torque. Therefore, a reasonable allocation of DQ-axis voltage can achieve maximum torque output.

\subsection{Constant torque region}

In the constant torque region, because the rotor speed is lower than the rated speed, the motor is not limited by the voltage and is only restricted by the rated current, therefore, DQ axis stator voltage increases linearly as the speed in Eq. 5.

$$
\begin{aligned}
& u_{s d}=-\omega_{e} \sigma L_{s} \sqrt{I_{s \max }^{2}-i_{\text {sd.rate }}^{2}} \\
& u_{s q}=\omega_{e} L_{s} i_{\text {sd.rate }}
\end{aligned}
$$

\subsection{Constant power region}

When the speed exceeds the rated speed, the motor is not limited by the voltage and current. As shown in Fig. 3, if the rotor flux command still maintain the original rating, motor run from A to B when the speed increased from wbase to ws1. It is clear that the operation voltage has exceeded the maximum voltage which makes the current response decrease a lot, and then leads the motor does not work. Therefore, in order to prevent the voltage saturation, the motor needs run from point B` to B by adjusting the flux command. This will not only meet the voltage and current limits, but also achieves the maximum torque output. 


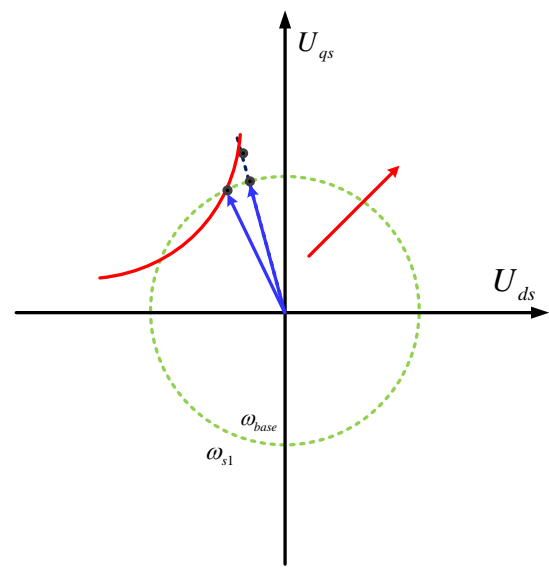

Fig. 3 the limit of current and voltage in the constant power region and constant voltage region From Fig. 3a, we can get distribution of DQ axis stator voltage in the constant power region which can achieve the maximum torque output in Eq. 6.

$$
\begin{aligned}
& u_{s d}=-\sqrt{\frac{\omega_{e}^{2} \sigma^{2} L_{s}^{2} I_{s \max }^{2}-\sigma^{2} V_{s \max }^{2}}{1-\sigma^{2}}} \\
& u_{s q}=\sqrt{\frac{V_{s \text { max }}^{2}-\omega_{e}^{2} \sigma^{2} L_{s}^{2} I_{s \max }^{2}}{1-\sigma^{2}}}
\end{aligned}
$$

\subsection{Constant voltage region}

As the speed continues to increase, the motor runs from $C$ to $D$ in Fig. 3b. It is clear that the torque output at point $\mathrm{D}$ is less than the torque output at point $\mathrm{C}$. Therefore, the optimum voltage vectors remain unchanged in the constant voltage region. From Fig. 3b, we can get distribution of DQ axis stator voltage in the constant voltage region which can achieve the maximum torque output in Eq. 7.

$$
\begin{aligned}
& u_{s d}=-V_{s \max } / \sqrt{2} \\
& u_{s q}=V_{s \max } / \sqrt{2}
\end{aligned}
$$

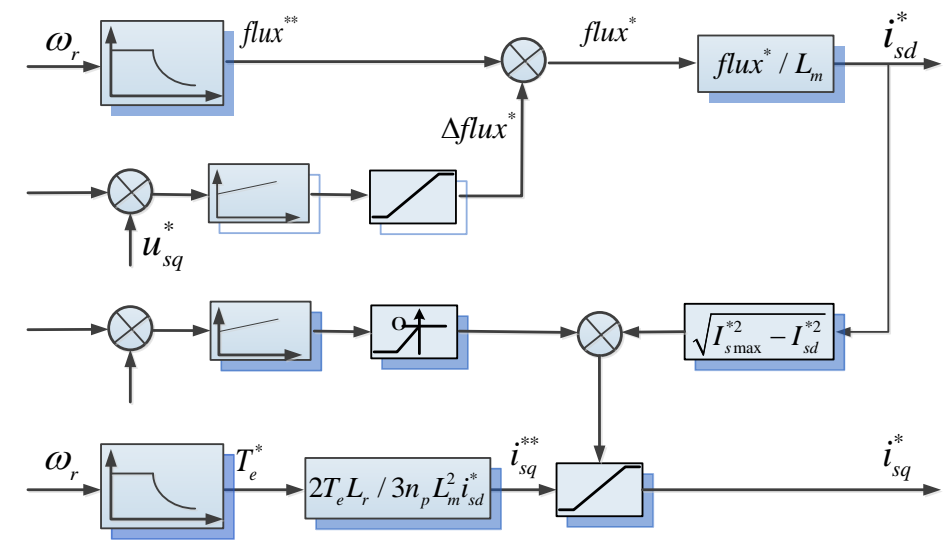

Fig. 4 the weakening control strategy of the maximum torque output in full region

In the above, the analysis of the induction motor DQ axis voltage distribution of the maximum torque output under full field is realized. Thereby we obtain weakening control strategy of the maximum torque output shown in Fig. 4. In order to make the stator voltage command equal to the maximum output voltage, we can adjust rotor flux command by the q-axis stator voltage regulator when the motor operates in the field weakening region which can reduce the q-axis stator voltage. When the motor operates in the constant voltage region, the maximum output torque is achieved by the d-axis stator voltage regulator. 


\section{Simulation results}

In order to verify the performance of the weakening control strategy, a simulation model based on MATLAB is constructed. The motor parameters used in the simulation are shown in table 1.

Table 1 motor parameters

\begin{tabular}{cccc}
\hline Parameters & Size & Parameters & Size \\
\hline Rated voltage /V & 380 & Stator resistance $/ \Omega$ & 1.9 \\
Rated power /kW & 5.5 & Rotor resistance $/ \Omega$ & 1.0097 \\
Rated current /A & 17.9 & Stator inductance $/ \mathrm{H}$ & 0.4472 \\
\hline Pole pairs & 2 & Rotor inductance $/ \mathrm{H}$ & 0.4472 \\
\hline Rated speed $(\mathrm{r} / \mathrm{min})$ & 1420 & Mutual inductance $/ \mathrm{H}$ & 0.4309 \\
\hline
\end{tabular}

The simulated motor rotor flux resulting from these two methods for rotor speeds ranging from 0 to $3000 \mathrm{rev} / \mathrm{min}$ are compared in Fig 5a, and large difference between them can be observed from the results. In addition, the simulated output torque from these two methods for rotor speeds ranging from 0 to $3000 \mathrm{rev} / \mathrm{min}$ are compared in Fig 5b. One can observe from the results shown in Fig. 5b that large output torque are resulted by applying the proposed method as the speed is increased.
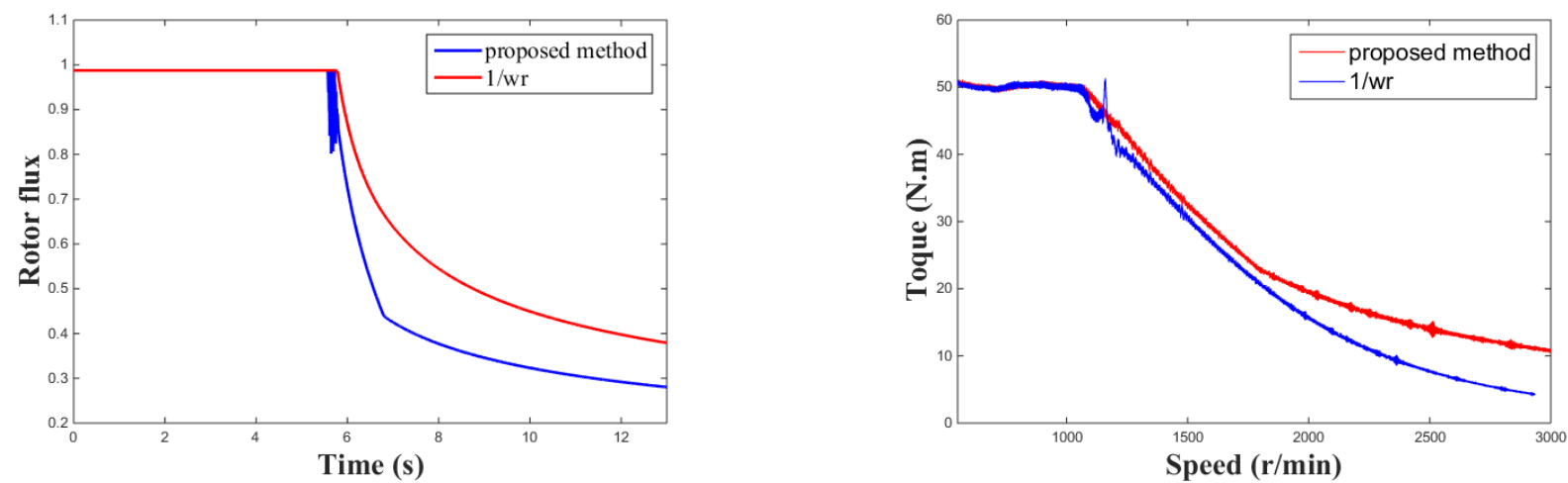

Fig. 5 (a) rotor flux determined by proposed method and conventional 1/wr method, (b) output torque by proposed method and conventional $1 /$ wr method
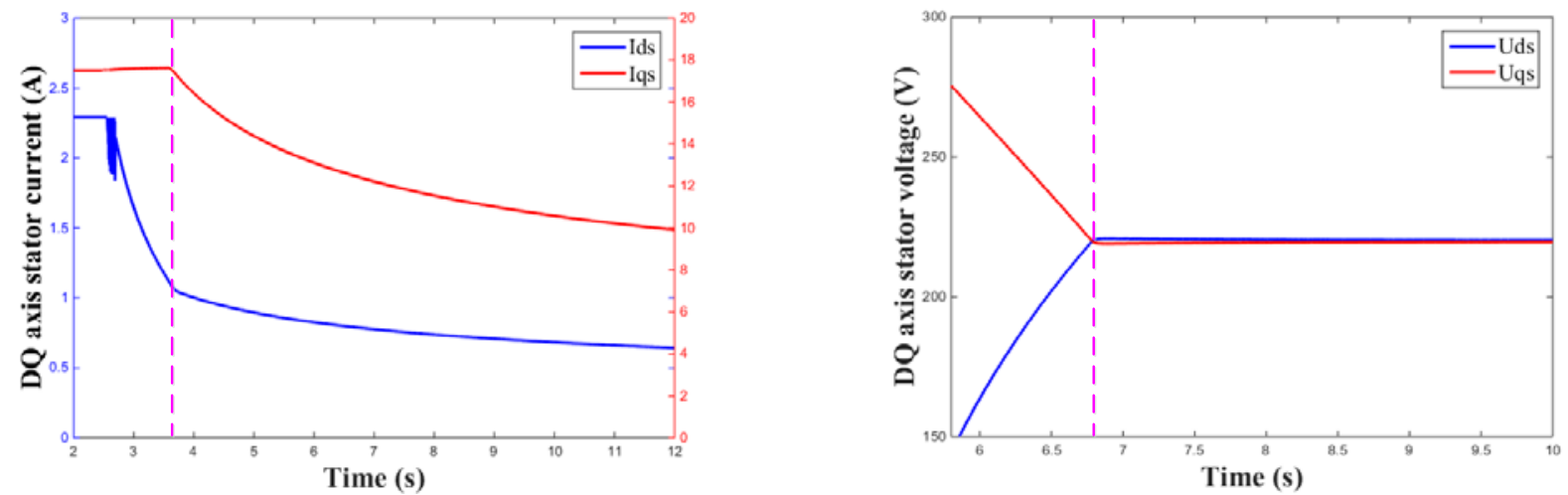

Fig. 6 (a) DQ axis stator current by proposed method, (b) DQ axis stator voltage by proposed method

Fig. 6a shows the DQ axis stator current by the proposed method. The flux current decreases and torque current increases in the constant power region. The flux current and torque current both decreases in the constant voltage region. Fig. 6b shows the DQ axis stator voltage by the proposed method. The simulation results same as the theoretical calculation. The d-axis voltage increases and the q-axis voltage decease in the constant power region. The d-axis voltage is equal to the q-axis voltage in the constant voltage region. 


\section{Conclusions}

In this paper, according to the steady state equation of induction motor, the restriction of current and voltage in field weakening region is studied. In addition, weakening control strategy is proposed based on DQ axis stator voltage regulation, to achieve the maximum torque output. The strategy does not require precise motor parameters and complex calculations to select the appropriate rotor flux. What' more, it has a good effect on improving the performance of induction motor in field weakening region.

\section{References}

[1] Novotny, D.W., and Lipo, T.A.: Vector control and dynamics of AC drives, Clarendon Press, Oxford, 1996

[2] A. M. Khambadkone and J. Holtz, Compensated synchronous PI current controller in over modulation range and six-step operation of space-vector modulation-based vector-controlled drives, IEEE Trans. Ind. Electron.,vol. 49, no. 3, pp. 574-580, Jun. 2002.

[3] J. K. Seok, “Field weakening control method in induction motor,” U.S. Patent 6104 159, Aug. 15, 2000.

[4] M. Mengoni, L. Zarri, A. Tani, G. Serra, and D. Casadei, “A comparison of four robust control schemes for field-weakening operation of induction motors,” IEEE Trans. Power Electron., vol. 27, no. 1, pp. 307-320, Jan.2012.

[5] L. Harnefors, K. Pietilainen, and L. Gertmar, “Torque-maximizing field-weakening control: design, analysis, and parameter selection,” IEEE Trans. Ind. Electron., vol. 48, no. 1, pp. 161-168, Feb. 2001.

[6] G. Gallegos-Lopez, F. S. Gunawan, and J. E. Walters, "Current control of induction machines in the field-weakened region,” IEEE Trans. Ind. Appl., vol. 43, no. 4, pp. 981-989, Jul./Aug. 2007. 